\title{
Analysis of GPS water vapor variability during the 2011 La Niña event over the western Pacific Ocean
}

\author{
Wayan Suparta $^{1, \star}$, Ahmad Iskandar ${ }^{1}$, Mandeep Singh Jit Singh ${ }^{1,2}$, Mohd. Alauddin Mohd. Ali ${ }^{1,2}$, \\ Baharudin Yatim ${ }^{1,3}$, Ahmad Norazhar Mohd Yatim ${ }^{4}$ \\ ${ }^{1}$ Universiti Kebangsaan Malaysia, Institute of Space Science (ANGKASA), Bangi, Selangor, Malaysia \\ ${ }^{2}$ Universiti Kebangsaan Malaysia, Department of Electrical, Electronic and System Engineering, Bangi, Selangor, Malaysia \\ ${ }^{3}$ Universiti Kebangsaan Malaysia, School of Applied Physics, Bangi, Selangor, Malaysia \\ ${ }^{4}$ Universiti Malaysia Sabah, School of Science and Technology, Environmental Science Prgm., Kota Kinabalu, Sabah, Malaysia
}

\author{
Article history \\ Received November 20, 2012; accepted May 15, 2013. \\ Subject classification: \\ Analysis, GPS precipitable water vapor, La Niña, Western Pacific Ocean, Global climate models.
}

\begin{abstract}
We analyzed the variability of global positioning system (GPS) water vapor during the 2011 La Niña events over the western Pacific Ocean. The precipitable water vapor ( $P W V$ ) derived from the UMSK (Malaysia) GPS station was investigated and compared with four other selected GPS stations: NTUS (Singapore), PIMO (Philippines), BAKO (Indonesia) and TOW2 (Australia). Analysis of the correlation between PWV and the sea-surface temperature anomaly (SSTa) on a weekly basis for the three La Niña cases of January-February-March, August-September-October, and October-November-December was used as an indicator of the influence of the El Niño Southern Oscillation. A good relationship between GPS PWV and SSTa for the Niño 4 region, with correlation coefficients between -0.91 and -0.94, was observed for the August-September-October and October-November-December cases. During the 2011 La Niña events, the water vapor was seen to increase to about $8.39 \mathrm{~mm}$ for the October-November-December case, with decreases of about $4.20 \mathrm{~mm}$ for the remaining months, compared to the mean 2011 value. This implies that during these events, the precipitation in the western Pacific is increased, due to stronger easterly trade winds blowing along the eastern Pacific Ocean than along the western Pacific, and a mass of warm water moving westwards, thereby increasing the evaporation.
\end{abstract}

\section{Introduction}

The El Niño Southern Oscillation (ENSO) is a complex phenomenon that results from an interaction between the ocean and the atmosphere in the equatorial Pacific Ocean. It consists of warm and cool phases. The warm phase is marked by an increase in the seasurface temperature (SST) to above $0.5^{\circ} \mathrm{C}$, which is called El Niño, while the cool phase is marked by a decrease in the SST to below $-0.5{ }^{\circ} \mathrm{C}$, which is called La Niña [Philander 1990, Trenberth 1997]. This phenome- non can influence climate change and have an impact on most regions around the world. For example, in a La Niña year, the tropical cyclone activity tends to increase, primarily in September and October, from east of the Philippines to the south coast of China [Chan 2000]. This La Niña episode causes the paths of typhoons in the western Pacific to shift more towards the mainland, which increases the chances of typhoons that can cause severe flooding and wind damage, along with the risks of landslides [Mekong River Commission 2011]. Another impact of La Niña is affects on the amount of rainfall when the SSTs surrounding Indonesia are cool, while the opposite tends to occur during the El-Niño-like drought conditions and when the Walker circulation is weakened, which results in anomalous surface easterlies across Indonesia [Hendon 2003]. Walker circulation is an artifact air flow that occurs in the lower atmosphere in the tropics that can be changed through changes in an ENSO episode. This circulation is contributed to by moving the mass of warm water from the east Pacific to the west, which results in increased evaporation in the western Pacific, especially during the phase of La Niña. For this reason, the west Pacific was selected as one of the regions to study the ENSO activity.

The ENSO phenomenon, including the La Niña phase, can be monitored using several indices, including the Southern Oscillation Index (SOI), the Oceanic Niño Index (ONI), and the Multivariate ENSO Index (MEI). The SOI is measured based on the differences between sea-level pressure anomalies at Tahiti and Darwin (Australia) [Ropelewski and Jones 1987]. The ONI is meas- 
ured based on the SST in the Pacific Ocean region, from central to eastern, as reported by Rasmusson and Carpenter [1982] and Reynolds and Smith [1995]. The MEI is measured based on the six main observed variables over the tropical Pacific. These six variables are sea-level pressure, zonal and meridional components of the surface wind, sea-surface temperature, surface air temperature, and total cloudiness fraction of the sky [Wolter and Timlin 1998]. Curtis and Adler [2000] conducted a study to construct the zonal gradient of precipitation in the equatorial Pacific to monitor the ENSO. Curtis and Adler [2000] used the Global Precipitation Climatology Project datasets to construct a gradient and to account for the variable nature of the ENSO events, which applied the moving block method to the SST and other atmospheric-oceanic variables.

In the present study, a global positioning system (GPS) approach is proposed for monitoring the ENSO activities. At present, GPS is not only used for geophysical and geodetic applications, but the GPS technique can also be used to estimate tropospheric parameters, such as precipitable water vapor (PWV) [e.g., Bevis et al. 1994]. The variability of the water vapor in the atmosphere causes a delay in GPS signals. This delay can be estimated to improve the positioning accuracy, and it is beneficial for meteorological applications. As the network of GPS stations is spreading around the world, it may be appealing to apply GPS signals to the investigation of the ENSO phenomenon. Therefore, this study aims to analyze the response of GPS water vapor variability on the ENSO phenomenon over the western Pacific Ocean. Kota Kinabalu, Sabah, which is situated on the tropical island of Borneo, was selected as the main base station for the GPS observations in this study. One of the significant aspects of this study was to improve our understanding for the prediction of ENSO activities, which is crucial for both the scientific community and the public [McPhaden et al. 2006].

\section{Methodology}

\subsection{Data and location}

The PWV data for the analysis was derived from five GPS stations and the surface meteorological station in the western Pacific Ocean. The GPS stations are located at University Malaysia Sabah Kota Kinabalu (UMSK) in Malaysia, the Nanyang Technological University (NTUS) in Singapore, the Manila Observatory (PIMO) in the Philippines, Bakosurtanal (BAKO) in Indonesia, and Townsville (TOW2) in Australia. Only two of these GPS stations (UMSK and NTUS) provided the surface meteorological data, whereas for the other stations, the data were collected from the closest of the GPS sites. To de-

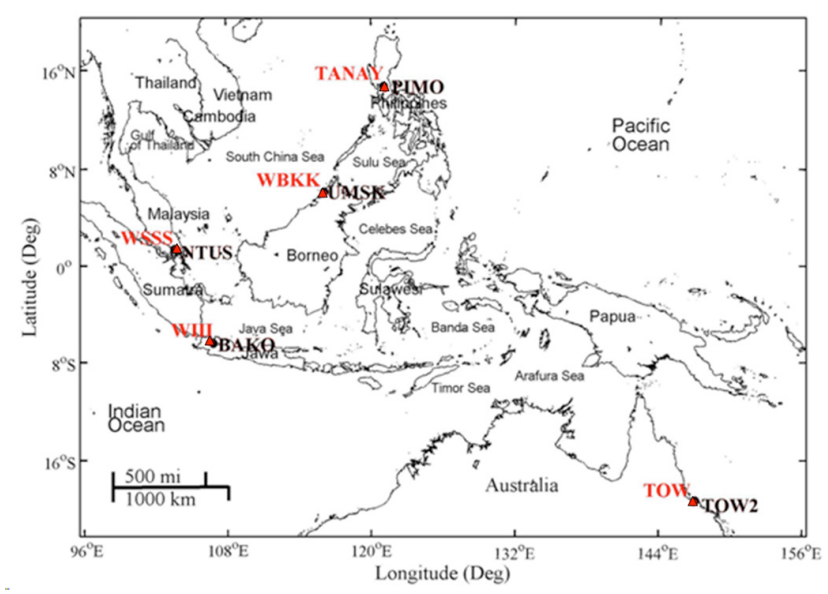

Figure 1. Location of the GPS and Radiosonde stations.

termine the PWV, the GPS data other than from UMSK were downloaded from the Scripps Orbit and Permanent Array Center website (http://sopac.ucsd.edu/) and the meteorological data were downloaded from the weather underground website (http: / / www.wunder ground.com). At the same time, PWV data recorded from Radiosonde measurements (RS PWV) were used to validate the PWV obtained from GPS. The RS data used were taken from closest of the GPS stations: WBKK (Kota Kinabalu, Malaysia), WSSS (Singapore), TANAY (Philippines), WIII (Indonesia), and TOW (Australia). The RS PWV data were provided courtesy of the University of Wyoming (USA).

To correlate the ENSO occurrence with the PWV responses, SST anomaly (SSTa) Oceanic Niño Index (ONI) data in the pathways of the Niño $3.4\left(5^{\circ} \mathrm{N}\right.$ to $5^{\circ} \mathrm{S}$, and $170^{\circ} \mathrm{W}$ to $\left.120^{\circ} \mathrm{W}\right)$ and Niño $4\left(5^{\circ} \mathrm{N}\right.$ to $5^{\circ} \mathrm{S}$, and $160^{\circ} \mathrm{E}$ to $150^{\circ} \mathrm{W}$ ) regions were used. SSTa is a good indicator for monitoring ENSO activity. The SSTa ONI data were taken from the Climate Prediction Center (CPC) National Oceanic and Atmospheric Administration (NOAA) (http: / / www.cpc.ncep.noaa.gov/ data / indices/). To study an ENSO using GPS, the analysis is focused on the data gathered during 2011. One of the reasons for the use of one-year data was due to the installation of a GPS receiver at UMSK in late March 2011. To overcome these temporal issues, the GPS data surrounding the UMSK station were analyzed together for comparison. On the other hand, UMSK station, which is located on the northwest coast of Kota Kinabalu Sabah facing the South China Sea, is the main base of ENSO studies in the western Pacific.

The PWV data have different resolutions for different GPS stations, due to the differences in the meteorological data intervals. In general, the resolution of all of the GPS data was $30 \mathrm{~s}$. The meteorological data at UMSK and NTUS stations have a 1-min interval, while tyhere is a 1-h interval for PIMO station. BAKO and TOW2 stations have the same time interval, at $30 \mathrm{~min}$. 


\begin{tabular}{|c|c|c|c|c|c|}
\hline $\begin{array}{l}\text { Station } \\
\text { (Country) }\end{array}$ & $\begin{array}{l}\text { Latitude } \\
\text { (deg) }\end{array}$ & $\begin{array}{l}\text { Longitude } \\
\quad \text { (deg) }\end{array}$ & $\begin{array}{l}\text { Height } \\
(\mathbf{m})\end{array}$ & $\begin{array}{c}\text { Type of GPS receiver } \\
\text { (year) }\end{array}$ & $\begin{array}{l}\text { Cut off elevation- } \\
\text { angle (deg) }\end{array}$ \\
\hline UMSK (Malaysia) & $6.03 \mathrm{~N}$ & $116.12 \mathrm{E}$ & 63.49 & Trimble NetR8 (2011) & 13 \\
\hline NTUS (Singapore) & $1.35 \mathrm{~N}$ & $103.68 \mathrm{E}$ & 75.38 & $\begin{array}{c}\text { LEICA } \\
\text { GRX1200GGPRO } \\
(2007)\end{array}$ & 0 \\
\hline PIMO (Philippines) & $14.64 \mathrm{~N}$ & $121.08 \mathrm{E}$ & 95.53 & $\begin{array}{c}\text { ASHTECH UZ-12 } \\
(2009)\end{array}$ & 4 \\
\hline BAKO (Indonesia) & $6.49 \mathrm{~S}$ & $106.85 \mathrm{E}$ & 158.2 & $\begin{array}{c}\text { LEICA } \\
\text { GRX1200+GNSS } \\
(2010)\end{array}$ & 0 \\
\hline TOW2 (Australia) & $19.06 \mathrm{~S}$ & $147.06 \mathrm{E}$ & 88.23 & $\begin{array}{c}\text { LEICA } \\
\text { GRX1200GGPRO } \\
(2010)\end{array}$ & 0 \\
\hline
\end{tabular}

Table 1. Geographical coordinates and instrument set-up of the GPS receivers used in this study.

The RS PWV data for all of the stations were collected twice a day (00:00 UT and 12:00 UT). The interval of SSTa provided by CPC NOAA was over one week.

Figure 1 shows the locations of the GPS (black circles) and RS (red triangles) stations. This Figure shows that UMSK is located at the geographical coordinates of $6.03^{\circ} \mathrm{N}$ latitude, $116.12^{\circ} \mathrm{E}$ longitude, and the ellipsoidal height of $63.49 \mathrm{~m}$. To be specific, geographical coordinates and instrument set-up of the GPS receivers used in this study are provided in Table 1 . Note that the position of the RS according to the scale provided in Figure 1 is very close. Therefore, the geographical coordinates of the RS and the surface meteorology stations, are provided in Tables 2 and 3, respectively. Based on the geographical coordinates, the closest distance between the GPS and RS was $13.57 \mathrm{~km}$ for the UMSK and WBKK stations, and $47.75 \mathrm{~km}$ for the BAKO and WIII stations.

\subsection{Data processing}

\subsubsection{GPS data}

The GPS consists of observation and navigation data. The observation data basically comprise phase measurements of dual GPS frequencies (L1 and L2, in cycles), C/A-code pseudorange measurements (in meters), Doppler frequency (in $\mathrm{Hz}$ ), and the signal-to-noise

\begin{tabular}{lccc}
\hline $\begin{array}{l}\text { Station } \\
\text { Country) }\end{array}$ & $\begin{array}{c}\text { Latitude } \\
(\mathbf{d e g})\end{array}$ & $\begin{array}{c}\text { Longitude } \\
(\mathbf{d e g})\end{array}$ & $\begin{array}{c}\text { Elevation } \\
(\mathbf{m})\end{array}$ \\
\hline WBKK (Malaysia) & $5.93 \mathrm{~N}$ & $116.05 \mathrm{E}$ & 3 \\
WSSS (Singapore) & $1.36 \mathrm{~N}$ & $103.98 \mathrm{E}$ & 16 \\
TANAY (Philippines) & $14.56 \mathrm{~N}$ & $121.36 \mathrm{E}$ & $106.65 \mathrm{E}$ \\
WIII (Indonesia) & $6.11 \mathrm{~S}$ & $146.76 \mathrm{E}$ & 8 \\
TOW (Australia) & $19.25 \mathrm{~S}$ & 9
\end{tabular}

Table 2. Geographical coordinates of the RS stations.

\begin{tabular}{lccr}
\hline $\begin{array}{l}\text { Station } \\
\text { (Country) }\end{array}$ & $\begin{array}{c}\text { Latitude } \\
(\mathbf{d e g})\end{array}$ & $\begin{array}{c}\text { Longitude } \\
(\mathbf{d e g})\end{array}$ & $\begin{array}{c}\text { Elevation } \\
(\mathbf{m})\end{array}$ \\
\hline Kota Kinabalu (Malaysia) & $5.90 \mathrm{~N}$ & $116.10 \mathrm{E}$ & 3.00 \\
NTUS (Singapore) & $1.35 \mathrm{~N}$ & $103.68 \mathrm{E}$ & 75.38 \\
Manila (Philippines) & $14.50 \mathrm{~N}$ & $121.00 \mathrm{E}$ & 21.00 \\
Soekarno-Hatta (Indonesia) & $6.10 \mathrm{~S}$ & $106.70 \mathrm{E}$ & 8.00 \\
Townsville (Australia) & $19.20 \mathrm{~S}$ & $146.80 \mathrm{E}$ & 6.00 \\
\hline
\end{tabular}

Table 3. Geographical coordinates of the meteorology stations. 
ratio of the signals. The navigation data comprise message GPS orbits from all of the satellites (almanac and ephemeris). Both of these formats are stored in receiver-independent exchange (RINEX) format. To check the quality of the GPS data, the Translation/ Editing/ Quality Check software from University NAVSTAR Consortium (http:/ / www.unavco.org/) was used. In addition, this software can be used to reduce the time for the data processing. The GPS data were then converted and rearranged from the RINEX type into ASCII or MAT files using the MATLAB program. The RINEX observation files in these archives were processed at 30 s sampling intervals.

\subsubsection{Meteorological data}

To estimate the GPS PWV with high accuracy and correct values, the meteorological data collocated with the GPS station are necessary. As both the GPS antenna and the meteorology sensors are not always collocated, a method to interpolate the meteorological data, such as temperature and pressure, at the GPS station together with the measurements from the meteorological stations is required. This interpolation is very important because the altitude of the station affects the variability of the pressure and temperature. For example, 8 mbar of difference in surface pressure will affect the ZHD by about $1 \mathrm{~mm}$. For this, Bai and Feng [2003] adopted the Klein Balting et al. [1999] equation to interpolate the relationship between the meteorological values at the sta- tion level (SL) and the mean sea level (MSL). Therefore, the heights between the GPS antenna and the meteorology sensor need to be considered. The equations for the interpolation proposed by Klein Balting et al. [1999] for the meteorological position are given as:

$$
\begin{gathered}
P_{S L}=P_{M S L}\left(1-2.26 \times 10^{-5} H_{m}\right)^{5.225} \\
T_{S L}=T_{M S L}-0.0065 H_{m} \\
R H_{S L}=R H_{M S L} e^{-6.396 H_{m}}
\end{gathered}
$$

where $H_{m}$ is the station height above sea level of the meteorology sensors, in meters, $P$ is the surface pressure, in mbar, $T$ is the surface temperature, in degrees Celsius, and $R H$ is the relative humidity, in percent. The meteorological data at sea level are then converted into GPS position at the MSL with the equations given as follows:

$$
\begin{gathered}
P_{M S L}=P_{S L} /\left(1-2.26 \times 10^{-5} H_{G P S}\right)^{5.225} \\
T_{M S L}=T_{S L}+0.0065 H_{G P S} \\
R H_{M S L}=R H_{S L} / e^{-6.396 H_{G P S}}
\end{gathered}
$$

where $H_{G P S}$ is the station height of the GPS antenna at MSL, in meters.

Figure 2 shows an example of the interpolation results of the meteorological data for the first week of Jan-
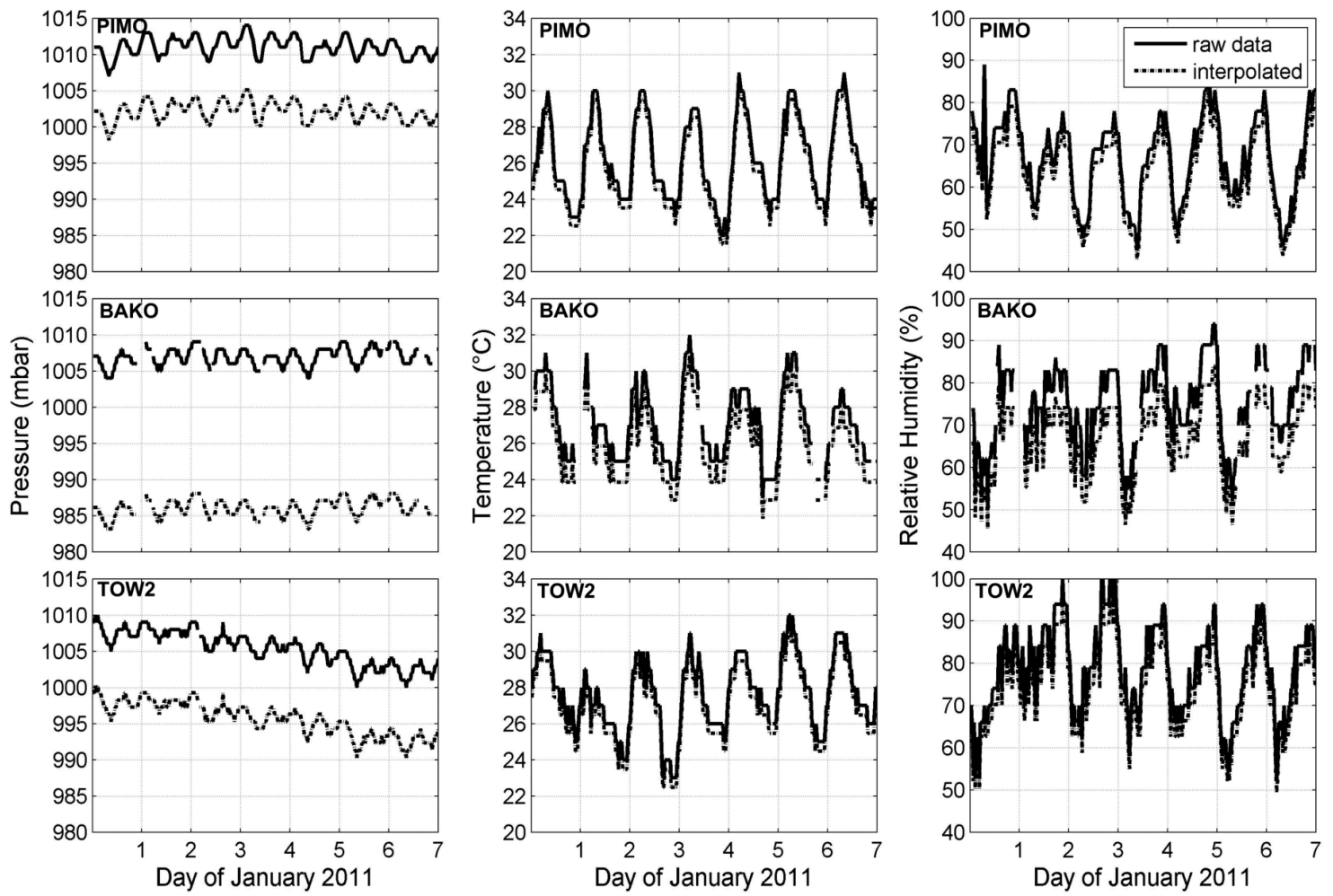

Figure 2. Interpolation of the meteorology data for seven days of January 2011 at three selected stations. 
uary, 2011. The interpolation results tend to be smaller than the original data, due to the altitude of the GPS stations, which are coincidently higher than the meteorological stations. From Figure 2, the surface pressure is a crucial parameter that changes significantly, which can be seen in the magnitude of the differences between before and after the interpolation process. BAKO is the station that has the biggest different for the surface pressure, of about $30.56 \mathrm{mbar}$, while the temperature and relative humidity are $3.61{ }^{\circ} \mathrm{C}$ and $7.85 \%$, respectively. The height differences between the GPS receiver and the meteorological stations for BAKO and WIII were $150.18 \mathrm{~m}$, while for PIMO and TANAY, and TOW2 and TOW they were $74.53 \mathrm{~m}$ and $82.23 \mathrm{~m}$, respectively. In addition, the height of topography might affect the meteorological data, mainly on the surface pressure parameter. Pressure is inversely proportional to height; the higher the position, the lower will be the pressure.

\subsection{3. $P W V$ data}

Both the GPS signals and the surface meteorological data (pressure, temperature and relative humidity) were processed to estimate the zenith tropospheric delay (ZTD). In the process of estimating the PWV, both the meteorological and GPS data must have the same interval time. The ZTD is comprised of the zenith hydrostatic delay (ZHD) and the zenith wet delay (ZWD). The ZTD was estimated based on the improved modified Hopfield model [Hofmann-Wellenhof et al. 2001, Suparta et al. 2008]. The ZHD was calculated using the Saastamoinen model [Saastamoinen 1972]. A Vienna mapping function (VMF1) was used to reduce the atmospheric bias in the ZTD estimation [Suparta et al. 2011]. The ZWD was computed by subtracting the ZTD from the ZHD. The ZWD was then transformed into an estimate of the PWV by using the surface temperature measured at a particular site. For details of the PWV calculations used in this study, readers are referred the Suparta et al. [2008]. The total of the PWV (in mm) from a receiver position to the top of the atmosphere was calculated based on the formula proposed by Bevis et al. [1994]. To process and analyze all of these parameters, a set of Matlab codes were used: namely, the tropospheric water vapor program (TroWav), as developed by Suparta et al. [2008, 2011] and Suparta [2010]. The equation to calculate the PWV is given as:

$$
P W V=\pi\left(T_{m}\right) Z W D
$$

with

$$
T_{m}=70.2+0.72 T_{K}
$$

where $\pi\left(T_{m}\right)$ is the conversion vector that varies with the local climate (e.g., geography, season and weather) and is dependent on a weighted mean temperature $\left(T_{m}\right), Z W D$ is in meters, and $T_{m}$ and $T_{\kappa}$ are the surfaceair temperature in Kelvin (K), respectively.

To study an ENSO activity with a response to the GPS water vapor variability, the correlation analysis of the Person's correlation coefficient $(r)$ was conducted between SSTa and GPS PWV. All of the data used were analyzed on a weekly basis, because the SSTa data are provided weekly by the NOAA. The data processing into a weekly format follows the GPS week by taking average values from the daily means.

\section{Result and discussion}

\section{1. $P W V$ variability}

Figure 3 shows the daily and weekly variations in PWV for the GPS and RS measurements during 2011. Based on the weekly data, the PWV for each station had a different variability, with the value between 11.55 $\mathrm{mm}$ and $63.03 \mathrm{~mm}$. The minimum of the GPS PWV was $26.43 \mathrm{~mm}$ for TOW2 station, and the maximum value was $56.39 \mathrm{~mm}$ for NTUS station. This is similar to the PWV value from the RS measurements, with a minimum for TOW station of $11.55 \mathrm{~mm}$ and the maximum for WSSS, of $63.03 \mathrm{~mm}$. One of the factors that led to high or low PWV was the geographic location. The lower geographic location (in terms of altitude) will obtain higher values of PWV. PWV content will decreases with increasing altitude. On the other hand, PWV varied because the intensity of the solar radiation in the low latitude regions are more exposures compared to the high latitudes.

The comparison of the trends of the PWV pattern between the GPS (UMSK) and the RS (WBKK) is also shown in Figure 3. During the dry season (from May to October), the PWV decreased at the stations located in Indonesia and Australia, to about $36.9 \mathrm{~mm}$ and 41.63 $\mathrm{mm}$, respectively. BAKO and TOW2 had similar weather conditions, with low temperatures during the dry season thus causing low of PWV. This is in contrast to the PWV in the station in the Philippines (PIMO), where the climate within the country consists of two major seasons; the dry season (from December to May) and the rainy season (from June to November). The dry season is subdivided further into the cool dry season (from December to February) and the hot dry season (from March to May). During the hot dry and rainy seasons, PWV increased due to the warmer temperature conditions. The Singapore (NTUS) station showed a difference in the PWV pattern between GPS and RS. From January to March, the PWV was lower than the other months due to the northeast monsoon season (from December to March) that brings more rainfalls and reduces the PWV. 

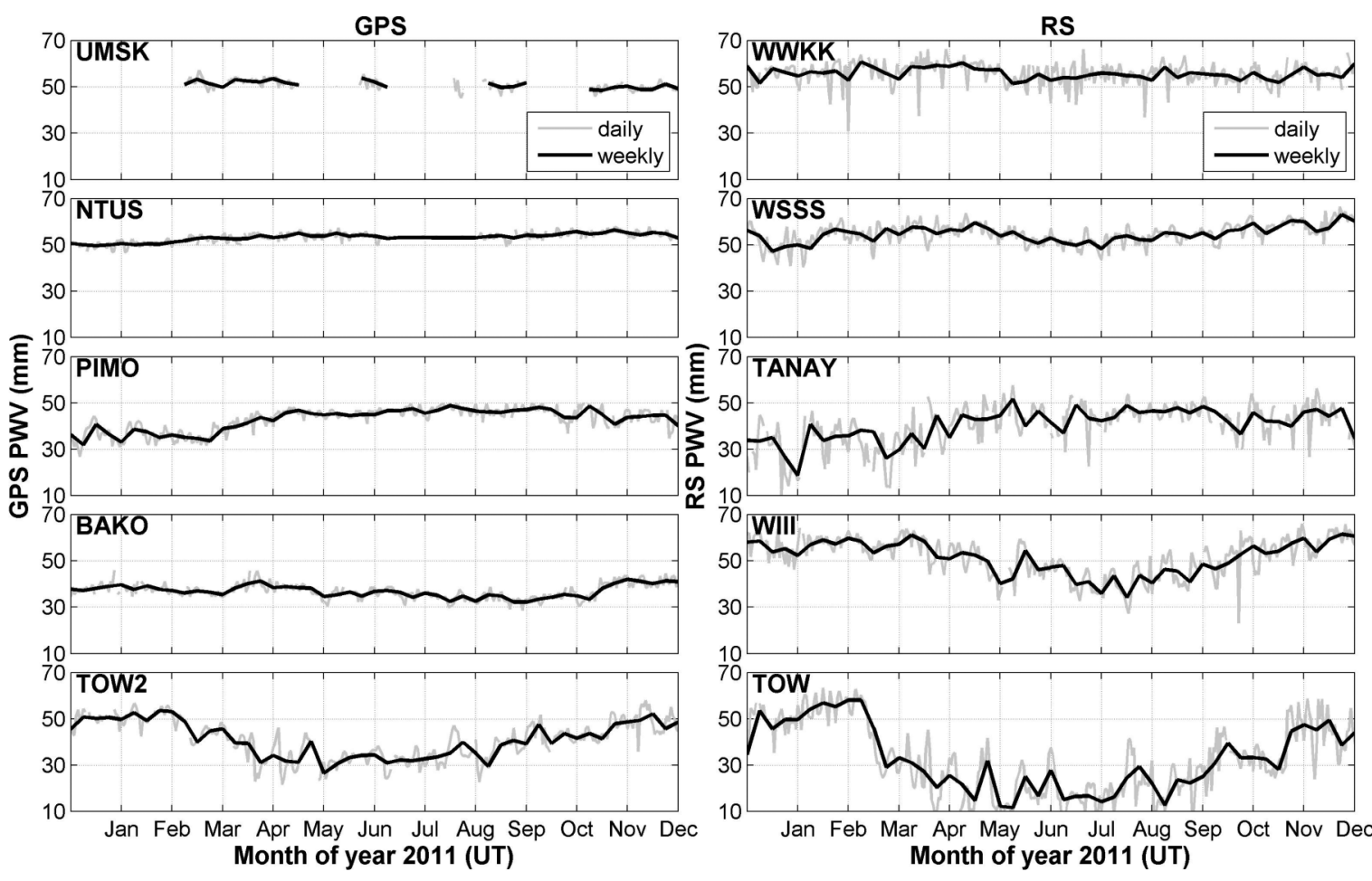

Figure 3. PWV variability from GPS and Radiosonde results for 2011.

\begin{tabular}{|c|c|c|c|c|}
\hline Station & Min & Max & Mean & SD \\
\hline UMSK (G) & 48.48 & 53.66 & 50.81 & 1.56 \\
\hline NTUS (G) & 48.30 & 56.39 & 52.97 & 1.78 \\
\hline PIMO (G) & 31.80 & 48.80 & 42.39 & 4.78 \\
\hline $\operatorname{BAKO}(\mathrm{G})$ & 32.21 & 42.02 & 36.90 & 2.53 \\
\hline TOW2 (G) & 26.43 & 53.49 & 41.63 & 7.92 \\
\hline WBKK (R) & 51.39 & 60.72 & 55.66 & 2.36 \\
\hline WSSS (R) & 47.18 & 63.03 & 54.61 & 3.45 \\
\hline TANAY (R) & 18.67 & 51.74 & 40.51 & 6.92 \\
\hline WIII (R) & 34.22 & 61.47 & 51.68 & 7.11 \\
\hline TOW (R) & 11.55 & 58.10 & 33.54 & 14.33 \\
\hline
\end{tabular}

Table 4. Analysis of statistical values of PWV for GPS and RS data for 2011. G and R are for GPS and Radiosonde, respectively. All statistical values are in $\mathrm{mm}$.

The minimum, maximum, mean, and SD for the GPS PWV and RS PWV at all of the stations on a weekly basis are summarized in Table 4. For all of the stations, these data show that the SD of the RS PWV data is greater and fluctuates more than those obtained by GPS. In addition to Figure 3, several RS PWV values are highly variable when they are under normal conditions. This indicates that the PWV obtained at five selected GPS stations during 2011 agrees better than those of RS. For example, the SD of PWV for GPS (UMSK) was $1.56 \mathrm{~mm}$ and for RS (WBKK) it was 2.36 $\mathrm{mm}$. The largest SD of $14.33 \mathrm{~mm}$ was observed at the TOW station (RS). The PWV variation can also be seen clearly in the daily variations (Figure 3 ). The local variation, such as for topography and distance from the sea, might affect the variation in PWV. The lower topographic areas have higher temperatures which causes greater evaporation and further affects the PWV. The TOW station located some $3 \mathrm{~km}$ from the sea (at a height of $9.0 \mathrm{~m}$ above sea level) had a higher temperature than the other stations. The sea is the largest source of evaporation. This evaporated water vapor will be pushed inland by the wind, and will further decrease the water vapor distribution. Therefore, the area near the sea contains more water vapor than in the areas distant from the sea. 

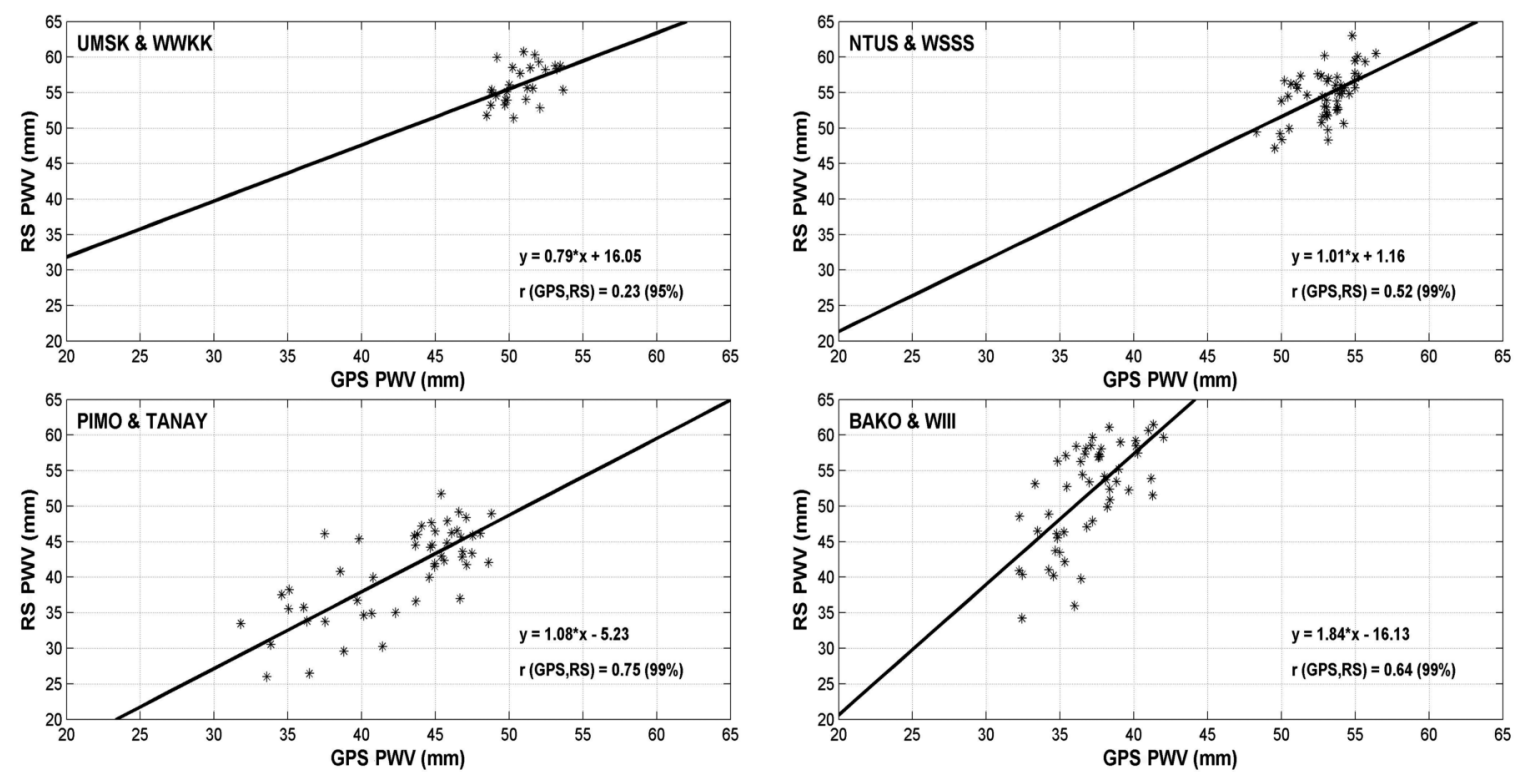

Figure 4. Scatterplot for the relationship between GPS PWV and RS PWV on a weekly basis for the year 2011.

\begin{tabular}{lccccccc}
\hline Quantity & Distance $(\mathbf{k m})$ & Min & Max & Mean & SD & RMSE & $r$ \\
\hline UMSK \& WBKK & 13.57 & -10.75 & -0.73 & -5.34 & 2.42 & 5.85 & 0.23 \\
NTUS \& WSSS & 33.37 & -8.23 & 4.88 & -1.64 & 2.94 & 3.35 & 0.52 \\
PIMO \& TANAY & 32.38 & -8.61 & 14.39 & 1.88 & 4.62 & 4.95 & 0.75 \\
BAKO \& WIII & 47.75 & -22.74 & 0.02 & -14.78 & 5.77 & 15.85 & 0.64 \\
TOW2 \& TOW & 39.49 & -9.22 & 18.77 & 8.1 & 7.62 & 11.07 & 0.93 \\
\hline
\end{tabular}

Table 5. Comparison of the differences between GPS PWV and RS PWV measurements for weekly intervals during 2011. *See text for the negative values.

\subsection{Comparison between GPS PWV and RS PWV} measurements

Before GPS PWV can be used for ENSO monitoring, the advantages of the PWV results need to be validated. Figure 4 shows a scatterplot for the relationship between the GPS PWV and the RS PWV, in weekly basis throughout year 2011. This relationship obtained moderate and strong correlations, with correlation coefficients between 0.52 (NTUS and WSSS) and 0.93 (TOW2 and TOW), that were significant at the $99 \%$ confidence level. The low relationship for the stations in Kota Kinabalu Sabah (UMSK and WBKK) was due to incomplete data at UMSK (see PWV variation at the top of Figure 3). The low correlation might be caused by differences in distance between the GPS and RS stations (see Table 5). Based on this correlation analysis, the GPS PWV variation agrees very well with that of the RS PWV, and therefore, it can be proposed for use for ENSO studies. The difference values for the minimum, maximum, mean, SD, RMSE and the correlation coefficient between GPS PWV and RS PWV for the weekly data for all of the stations are summarized in Table 5. The difference value was obtained by subtracting the GPS PWV from RS PWV and the negative value obtained shows that the RS PWV is greater than the GPS PWV.

\subsection{SSTa variability}

Figure 5 shows the SSTa ONI variability for the Niño 3.4 and Niño 4 regions throughout the year 2011. From Figure 5, only the La Niña phase recorded in the Niño 3.4 and Niño 4 regions were based on the NOAA definition [JMA 1991]. The NOAA defines that ENSO is characterized by a five consecutive three-month running mean of SSTa in the Niño 3.4 region that is above $+0.5^{\circ} \mathrm{C}$ (El

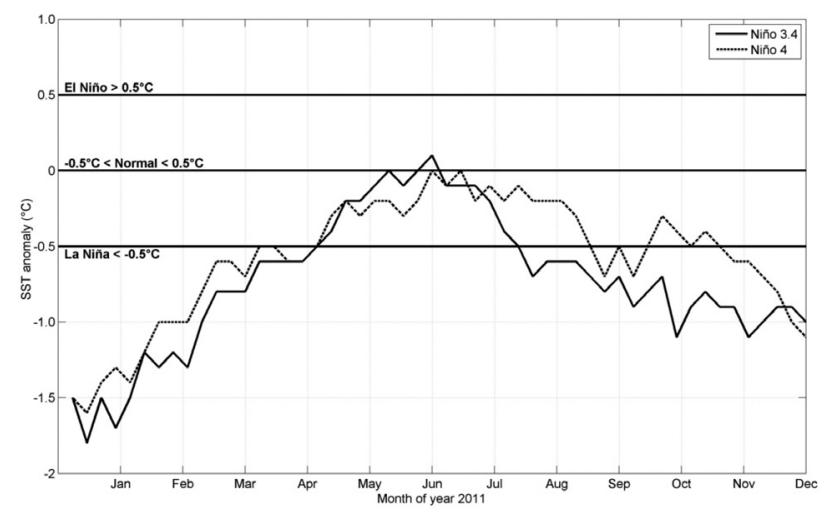

Figure 5. SSTa variability for the Niño 3.4 and Niño 4 regions in 2011. 

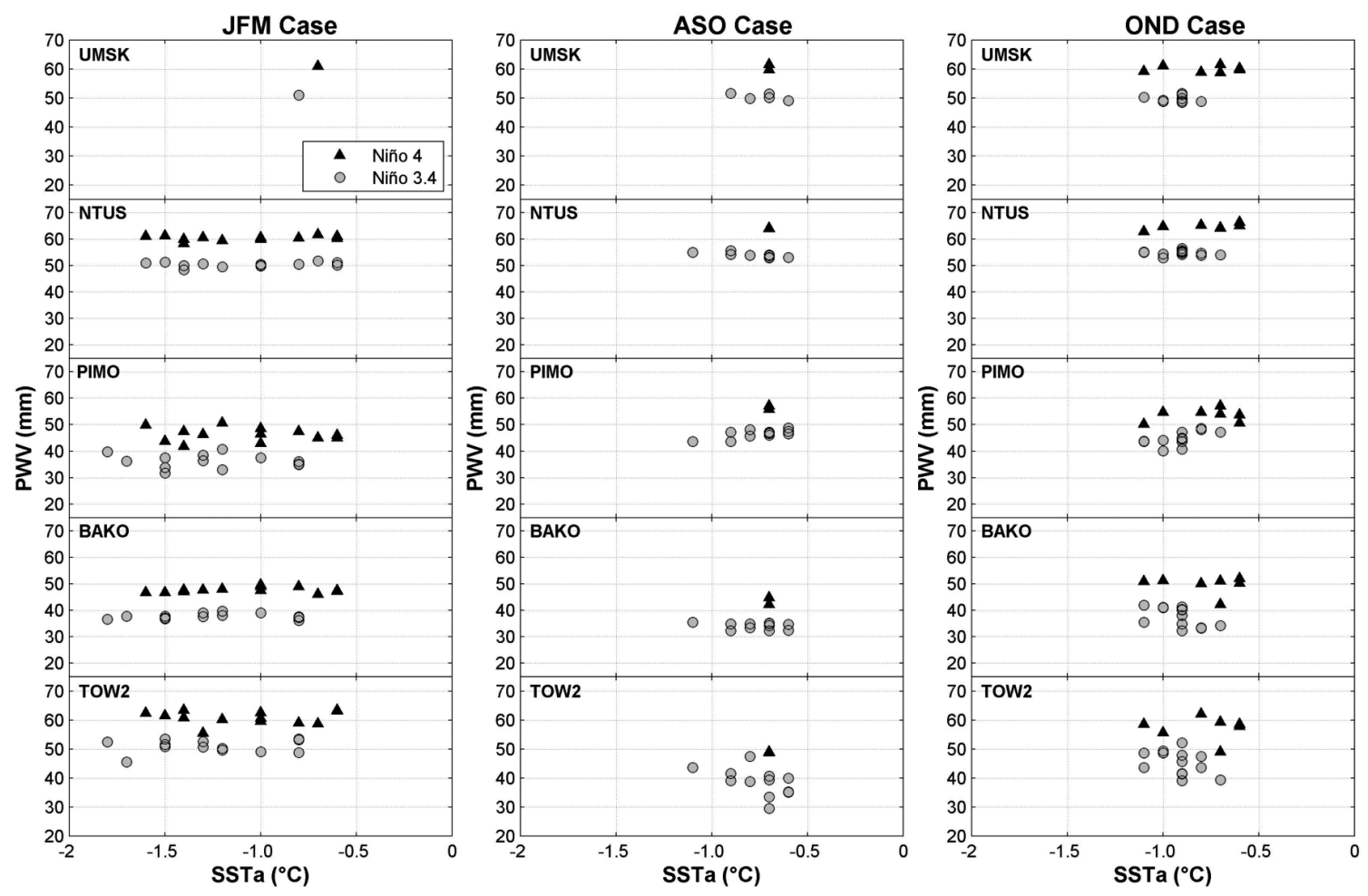

Figure 6. Scatterplot of the relationship between GPS PWV and SSTa below $-0.5{ }^{\circ} \mathrm{C}$ for the Niño 4 and Niño 3.4 regions. Note that to contrast the trends between the two Niños regions, PWV values for the Niño 4 region have an added $10 \mathrm{~mm}$. For JFM case, only one set of PWV data (on a weekly basis) was recorded at UMSK station due to the installation of a GPS receiver in late March 2011.

Niño phase) or below $-0.5^{\circ} \mathrm{C}$ (La Niña phase). Based on the SSTa for Niño 3.4 region, La Niña cases occur as many as two times: from January to April and from August to December. However, the SSTa for Niño 4 occurs three times during January-April, September and November-December. From both Niños, the La Niña phase in early 2011 was started from strong to weak, with SSTa of $-1.8^{\circ} \mathrm{C}$ (Niño 3.4) and $-1.6{ }^{\circ} \mathrm{C}$ (Niño 4). In contrast, at the end of the year, the phase was weak to strong. From Figure 5, the SSTa pattern that represents the La Niña intensity is expected to increase for the next year.

3.4. Analysis of the PWV response on the La Niña event A rational response of the GPS PWV on the ENSO event in the tropical Pacific is applied using the SSTa data obtained from CPC NOAA. Figure 6 shows the scatterplot of the relationship between GPS PWV and SSTa below $-0.5^{\circ} \mathrm{C}$ for the Niño 3.4 and Niño 4 regions. Referring to Figure 5, to indicate the strength of the relationship between the La Niña occurrence and SSTa, the event is divided into three cases: January-FebruaryMarch (JFM), August-September-October (ASO), and October-November-December (OND). The three cases selected were based on the negative phase of ENSO. For the case of JFM, the relationship between GPS PWV and SSTa both for the Niño 3.4 and Niño 4 regions at all of the stations are not correlated. This is probably because the intensity of La Niña is getting weaker, which has an insignificant effect on PWV.

For the case of ASO, the relationship between GPS

\begin{tabular}{|c|c|c|c|c|c|c|c|c|c|c|}
\hline \multirow[t]{2}{*}{ Site } & \multicolumn{2}{|c|}{ Case JFM } & \multicolumn{4}{|c|}{ Case ASO } & \multicolumn{4}{|c|}{ Case OND } \\
\hline & Niño 3.4 & Niño 4 & Niño 3.4 & Conf $(\%)$ & Niño 4 & Conf $(\%)$ & Niño 3.4 & Conf $(\%)$ & Niño 4 & Conf $(\%)$ \\
\hline UMSK & - & - & -0.12 & No & -0.95 & 99 & -0.25 & No & -0.91 & 99 \\
\hline NTUS & 0.22 & 0.23 & -0.87 & 99 & -0.96 & 99 & -0.13 & No & -0.90 & 99 \\
\hline PIMO & -0.14 & -0.11 & -0.82 & 99 & -0.95 & 99 & 0.61 & 97.5 & -0.90 & 99 \\
\hline BAKO & 0.08 & 0.19 & -0.86 & 99 & -0.95 & 99 & -0.54 & 95 & -0.94 & 99 \\
\hline TOW2 & 0.16 & 0.05 & -0.88 & 99 & -0.96 & 99 & -0.39 & 90 & -0.90 & 99 \\
\hline
\end{tabular}

Table 6. Correlation coefficients between GPS PWV and SSTa below $-0.5^{\circ} \mathrm{C}$ for the three La Niña cases during 2011. ${ }^{\star}$ Conf, confidence level. There is no correlation for the case of JFM at both Niño regions. No correlation of Niño 3.4 region was also found for UMSK station for ASO and OND cases, and NTUS station for OND case. 
PWV and SSTa for both Niño regions has a good relationship, with correlation coefficients between -0.82 and -0.96 , with an exception for UMSK station for the Niño 3.4 region. The strong relationship in the case of ASO was due to only two SSTa data recorded below $0.5^{\circ} \mathrm{C}$ for the Niño 4 region (see Figure 6 ). For the OND case, the correlation varies from weak to strong. Very weak correlations were observed at the UMSK, NTUS and TOW2 stations for the Niño 3.4 region, with correlation coefficients of $-0.25,-0.13$ and -0.39 , respectively, and moderate correlations were observed at the PIMO (with positive correlation) and BAKO stations. Details of the relationships between GPS PWV and SSTa for the negative phase of 2011 at all of the stations are compiled in Table 6. As indicated in Table 6, PWV has a reverse relationship with SSTa. The negative correlation indicates that during the 2011 La Niña phase, PWV was increased because the warm air mass in the central Pacific moved to the west Pacific. This implies that evaporation in the western Pacific will strengthen the PWV level. The physical explanation of how GPS PWV decreases during these events is presented in the following section.

\subsection{Physical interpretation of $P W V$ during the ENSO} event

To explain the GPS PWV response to the ENSO during the La Niña phase, the precipitation rate taken from the Tropical Rainfall Measuring Mission (TRMM) is compared. The data estimated by TRMM-3B42.007 with a 3-h resolution were taken from the National Aeronautic and Space Administration (NASA) (http:/ / gdata1.sci.gsfc.nasa.gov/daac-bin/G3/gui.cgi?instance _id=TRMM_3-Hourly). Figure 7 shows the average rate of precipitation (in $\mathrm{mm} / \mathrm{h}$ ) analyzed from the TRMM Online Visualization and Analysis System (TOVAS) NASA Goddard Space Flight Center (GSFC) for the region of $96^{\circ} \mathrm{E}-156^{\circ} \mathrm{E}, 22^{\circ} \mathrm{S}-20^{\circ} \mathrm{N}$ every three months. The precipitation at each station can also be estimated by TOVAS from the averaged time-series of the Lat-Lon map given in Table 1. Here, the analyses are focused on the three La Niña cases of JFM, ASO and OND.

For the case of JFM, the average estimation of precipitation over all of the stations is from $0.361 \mathrm{~mm} / \mathrm{h}$ to $1.295 \mathrm{~mm} / \mathrm{h}$, with an exception at the PIMO station (below $0.361 \mathrm{~mm} / \mathrm{h}$ ). In this case, the highest rate of precipitation occurred for UMSK station, which reached to $1.295 \mathrm{~mm} / \mathrm{h}$. The high precipitation is also characterized by the low PWV value to $30 \mathrm{~mm}$ in February (see Figure 3). The decrease in PWV at this station is expected due to the effects of the wet season in Kota Kinabalu, Sabah. Although PIMO had low precipitation, some areas in the Philippines region (as seen
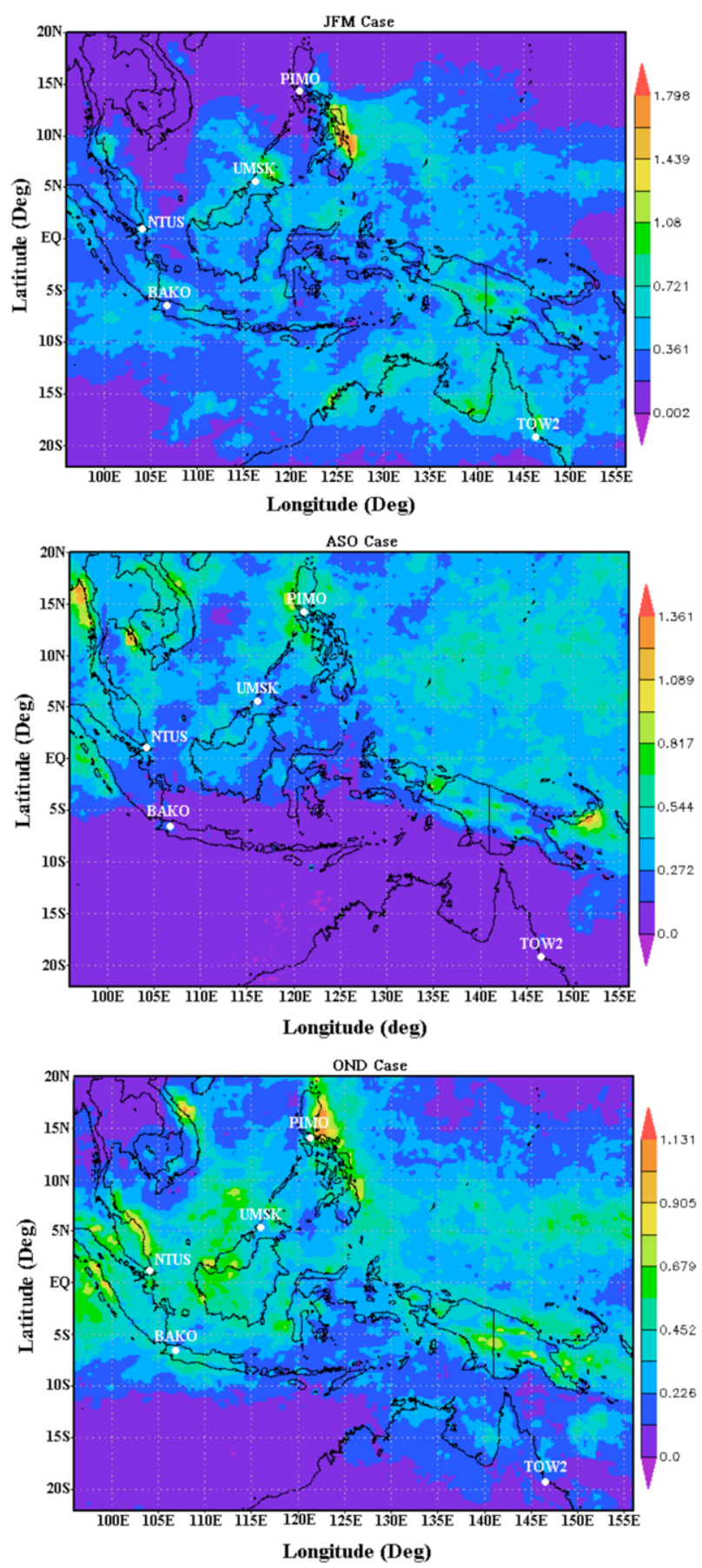

Figure 7. The average rate precipitation measured by TRMM$3 \mathrm{~B} 42.007$ covering the region of $96^{\circ} \mathrm{E}-156^{\circ} \mathrm{E}, 22^{\circ} \mathrm{S}-20^{\circ} \mathrm{N}$ for the cases of JFM, ASO and OND.

in Figure 7) showed a high rate of precipitation, of between $1.439 \mathrm{~mm} / \mathrm{h}$ and $1.798 \mathrm{~mm} / \mathrm{h}$. This precipitation corresponded to the La Niña event that generated the average amount of rainfall over this area that reached $100 \mathrm{~mm} /$ day (from 20 December 2010 to 19 January 2011). This rainfall was estimated from the TRMMbased, near-real-time Multi-satellite Precipitation Analysis (TMPA) of NASA GSFC (http: / / trmm.gsfc. nasa.gov/publications_dir/philippine_flooding_20dec 10-19jan11.html).

The high precipitation condition for the ASO case 
only happened for the NTUS, UMSK and PIMO stations, with a maximum rate of $0.817 \mathrm{~mm} / \mathrm{h}$, while precipitation for the BAKO and TOW2 stations, was estimated as below $0.272 \mathrm{~mm} / \mathrm{h}$. In this case, a series of tropical cyclones brought heavy rains. This storm originated from sea level in the Philippines and moved to the west, as recorded by TMPA NASA GSFC, which caused a heavy rainfall in the Philippines, with rainfall totals that appeared over Hainan that ranged as high as $650 \mathrm{~mm}$ (23 September 2011 to 5 October 2011). The storm was accompanied by the presence of the La Niña event, which also brought rain from the Pacific Ocean, and the PWV reached up to $45 \mathrm{~mm}$ (see Figure 3). For the OND case, the precipitation rate was estimated between $0.226 \mathrm{~mm} / \mathrm{h}$ and $1.131 \mathrm{~mm} / \mathrm{h}$. Similar to the previous cases, the Philippines have the highest rate of precipitation over the other areas, which indicates that La Niña had a significant influence on the amount of precipitation in the Philippines.

In general, if the precipitation is high, then the PWV will decrease. This appears to contrast with the La Niña events in 2011 (see Figures 3 and 7) where PWV and precipitation were equally increased. This can also be seen in the results of the correlation between PWV and SSTa, where the majority of the correlation was negative. This means that PWV increased along with the low SSTa (strong La Niña event). During these events, strong trade winds from the central Pacific towards the west Pacific can cause the mass of warm water in the central Pacific to move to the west Pacific and result in an increase in the evaporation. This is consistent with the interpretation of Bjerknes [1969] regarding the transition of ENSO. At the same time, this phenomenon is possibly accompanied by a modified moisture transport in the atmosphere that affected the GPS signals.

\section{Conclusions}

This study reports the response of GPS water vapor during an ENSO event in 2011, specifically the La Niña phase in the western Pacific Ocean. Using weekly data, the analysis was divided into the three cases of $\mathrm{La}$ Niña. The explanations of the La Niña effects on the GPS PWV can be summarized as follows.

Good responses of GPS PWV on the SSTa was observed for the cases of ASO and OND, while for the JFM case, they did not correlate significantly due to the weaker intensity of La Niña. For the case of ASO, the relationship between GPS PWV and SSTa for the Niño 3.4 and Niño 4 regions at all of the stations demonstrated a strong correlation, except for UMSK station. For the case of OND, moderate correlation was observed for PIMO and BAKO stations, with coefficient correlations of 0.61 and -0.54 , respectively. However, in the case of OND for Niño 3.4, only the PIMO station showed a positive correlation because of the cold surface temperature in that station. The relationship between GPS PWV and SSTa from the Niño 4 region of both the ASO and OND cases at all of the stations was stronger, with correlation coefficients between -0.90 and -0.96 . The SSTa from the Niño 4 region gave a better response than that of the Niño 3.4 region due to its location along the west Pacific. In general, from the analysis, it is viable to use the GPS PWV to study the ENSO activities.

As a conclusion, the amount of water vapor in the western Pacific Ocean was demonstrated to increase significantly during the 2011 La Niña events. These events can cause strong trade winds and the mass of warm water moving from the central to the west $\mathrm{Pa}$ cific results in an increase in the evaporation in the western Pacific. To get a better insight into the understanding of the response of GPS PWV during ENSO events, long-term data need to be analyzed to clarify the physical mechanism.

Acknowledgements. This study was funded by the Ministry of Higher Education Malaysia (MOHE) under grant UKM-LL-08FGRS0212-2010. The authors would like to express their gratitude to the School of Science and Technology, University Malaysia Sabah (UMS), for the maintenance of the GPS receiver and the meteorological systems. We would like to thank the Institute of Space Science (ANGKASA), UKM for supporting the equipment, the National Oceanic and Atmospheric Administration (NOAA) for archiving the SST data, Wyoming University for the PWV Radiosonde data, and the National Aeronautic and Space Administration (NASA) for precipitation data. We also thank the two anonymous reviewers for their constructive comments, which substantially contributed to the improving of the quality of the manuscript.

\section{References}

Bai, Z., and Y. Feng (2003). GPS water vapor estimation using interpolated surface meteorological data from Australian automatic weather stations, J. Global Positioning Syst., 2, 83-89.

Bevis, M., S. Businger and S. Chiswel (1994). GPS meteorology: mapping zenith wet delay onto precipitable water, J. Appl. Meteorol., 33, 379-386.

Bjeknes, J (1969). Atmospheric teleconnections from the equatorial Pacific, Mont. Weat. Rev., 97, 163-172.

Chan, J.C.L. (2000). Tropical cyclone activity over the western North Pacific associated with El Niño and La Niña events, J. Climate, 13, 2960-2972.

Curtis, S., and R. Adler (2000). ENSO indices based on patterns of satellite-derived precipitation, J. Climate, 13, 2786-2793.

Hendon, H.H. (2003). Indonesian rainfall variability: impact of ENSO and local air-sea interaction, J Climate, 16, 1775-1790.

Hofmann-Wellenhof, B., H. Lichtenegger and J. Collins 
(2001). Global Positioning System: Theory and Practice, $7^{\text {th }}$ revised edition, Springer.

JMA (Japan Meteorological Agency), Marine Department (1991). Climate Charts of Sea Surface Temperatures of the Western North Pacific and the Global Ocean, 51 pp.

Klein Baltink, H., H.J.P. Derks, A.C.A.P. van Lammeren, B.A.C. Ambrosius, A.G.A. van der Hoeven, H. van der Marel, F. Kleijer and A.J.M. Kosters (1999). Water Vapour from GPS Tropospheric Delay Estimates, In: GPS Water Vapour Meteorology, Beleids Commissie Remote Sensing (BCRS), chapter 2, pp. 3-11.

McPhaden, M.J., S.E. Zebiak and M.H. Glantz (2006). ENSO an integrating concept in Earth Science, Science, $314,1740-1745$.

Mekong River Commission (2011). Flood situation report, November 2011, MRC Technical Paper No. 36, Mekong River Commission, 57 pp.

Philander, S.G. (1990). El Niño, La Niña, and Southern Oscillation, Academic Press, Sandiego, CA, 289 pp.

Rasmusson, E.M., and T.H. Carpenter (1982). Variations in tropical sea surface temperature and surface wind fields associated with the Southern Oscillation/El Niño, Mon. Wea. Rev., 110, 354-384.

Reynolds, R.W., and T.M. Smith (1995). A high-resolution global sea surface temperature climatology, J. Climate, 8, 1571-1583.

Ropelewski, C.F., and P.D. Jones (1987). An extension of the Tahiti-Darwin Southern Oscillation Index, Mon. Wea. Rev., 115, 2161-2165.

Saastamoinen, J. (1972). Introduction to practical computation of astronomical refraction, Bull. Geodesique, 106, 383-397.

Suparta, W., Z.A. Abdul Rashid, M.A. Mohd Ali, B. Yatim and G.J. Fraser (2008). Observation of Antarctic precipitable water vapor and its response to the solar activity based on GPS sensing, J. Atmos. SolTerr. Phys., 70, 1419-1447.

Suparta, W. (2010). Using a global positioning system to estimate precipitable water vapor in Antarctica, Polar Geogr., 33, 63-79.

Suparta, W., M.S. Jit Singh, M.A. Mohd. Ali, B. Yatim and A.N. Mohd Yatim (2011). GPS water vapor monitoring and TroWav updated for ENSO studies, In: Proceeding International Conference on Instrumentation, Communication, Information Technology and Biomedical Engineering (ICICI-BME 2011), 35-39.

Trenberth, K.E. (1997). The definition of El Niño, Bull. Amer. Met. Soc., 78, 2771-2777.

Wolter, K., and M. S. Timlin (1998). Measuring the strength of ENSO events: How does 1997/ 98 rang?, Weather, 53, 315-324.
${ }^{\star}$ Corresponding author: Wayan Suparta,

Universiti Kebangsaan Malaysia, Institute of Space Science (ANGKASA), Bangi, Selangor, Malaysia; email: wayan@ukm.my.

C 2013 by the Istituto Nazionale di Geofisica e Vulcanologia. All rights reserved. 